\title{
Fabric along the NEEM ice core, Greenland, and its comparison with GRIP and NGRIP ice cores
}

\author{
M. Montagnat ${ }^{1,2}$, N. Azuma ${ }^{3}$, D. Dahl-Jensen ${ }^{4}$, J. Eichler ${ }^{5,6}$, S. Fujita ${ }^{7}$, F. Gillet-Chaulet ${ }^{1,2}$, S. Kipfstuhl ${ }^{5}$, D. Samyn ${ }^{3}$, \\ A. Svensson ${ }^{4}$, and I. Weikusat ${ }^{5}$ \\ ${ }^{1}$ CNRS, LGGE, UMR5183, 38041 Grenoble, France \\ ${ }^{2}$ Univ. Grenoble Alpes, LGGE, 38041 Grenoble, France \\ ${ }^{3}$ Department of Mechanical Engineering, Nagaoka University of Technology, 1603-1 Kamitomioka, Nagaoka 940-2188, \\ Niigata, Japan \\ ${ }^{4}$ Niels Bohr Institute, Ice and Climate Research, University of Copenhagen, Juliane Maries Vej 30, \\ 2100 Copenhagen, Denmark \\ ${ }^{5}$ Alfred Wegener Institute for Polar and Marine Research, Columbusstrasse, 27568 Bremerhaven, Germany \\ ${ }^{6}$ Fachbereich Physik, Freie Universitat Berlin, Arnimallee 14, 14195 Berlin, Germany \\ ${ }^{7}$ National Institute of Polar Research, Research Organization of Information and Systems (ROIS), Midori-chou 10-3, \\ Tachikawa, Tokyo, 190-8518, Japan
}

Correspondence to: M. Montagnat (montagnat@lgge.obs.ujf-grenoble.fr)

Received: 4 November 2013 - Published in The Cryosphere Discuss.: 14 January 2014

Revised: 15 May 2014 - Accepted: 16 May 2014 - Published: 1 July 2014

\begin{abstract}
Fabric (distribution of crystallographic orientations) along the full NEEM ice core, Greenland was measured in the field by an automatic ice texture analyzer every $10 \mathrm{~m}$, from $33 \mathrm{~m}$ down to $2461 \mathrm{~m}$ depth. The fabric evolves from a slightly anisotropic fabric at the top, toward a strong single maximum at about $2300 \mathrm{~m}$, which is typical of a deformation pattern mostly driven by uniaxial compression and simple shearing. A sharp increase in the fabric strengthening rate is observed at the Holocene to Wisconsin (HW) climatic transition. From a simple model we estimate that this depth is located at a transition from a state dominated by vertical compression to a state dominated by vertical shear. Comparisons are made to two others ice cores drilled along the same ridge; the GRIP ice core, drilled at the summit of the ice sheet, and the NGRIP ice core, drilled $325 \mathrm{~km}$ to the NNW of the summit along the ridge, and $365 \mathrm{~km}$ upstream from NEEM. This comparison tends to demonstrate that the ice viscosity change with the $\mathrm{HW}$ climatic transition must be associated with the shear-dominated state to induce the abrupt fabric strengthening observed at NEEM. This comparison therefore reflects the increasing role of shear deformation on the coring site when moving NW along the ridge from GRIP to NGRIP and NEEM. The difference in fabric profiles be-
\end{abstract}

tween NEEM and NGRIP also evidences a stronger lateral extension associated with a sharper ridge at NGRIP. Further along the core, centimeter scale abrupt texture (fabric and microstructure) variations are observed in the bottom part of the core. Their positions are in good agreement with the observed folding layers in Dahl-Jensen et al. (2013).

\section{Introduction}

Crystal preferred orientation, or fabric, analyses along ice cores drilled in polar ice sheets are highly necessary to provide information about conditions of deformation along ice cores. While grain size evolution is traditionally associated with climatic changes (Duval and Lorius, 1980; Durand et al., 2006b), the fabric evolution depends primarily on the dominant strain conditions, and the fabric strength is often related to the cumulative strain (Alley, 1988; Budd and Jacka, 1989).

Under deformation conditions typical for most of the deep ice cores drilled in Greenland and Antarctica, the $c$ axis distribution of the ice crystals rotates towards a compression axis, perpendicular to a shear direction, and away from a 
tension axis (Gow and Williamson, 1976; Alley, 1988; Paterson, 1994). The fabric profile along a core is then a good candidate to evaluate the nature of the flow and to extract irregularities in the deformation history if present. In the specific case of a perfect dome, the ice deforms solely by uniaxial compression along the vertical direction (Alley, 1988). Fabric therefore concentrates toward the compression direction with increasing compressive strain with depth. This is qualitatively confirmed by the fabrics measured along cores, such as those of Greenland GRIP (Thorsteinsson et al., 1997), and Antarctic Dome Fuji (Azuma et al., 1999), EPICA Dome C (Wang et al., 2003; Durand et al., 2009), and Talos Dome (Montagnat et al., 2012), which are all located close to topographic domes. At NGRIP, Greenland (Wang et al., 2002), Vostok (Lipenkov et al., 1989), and EDML (Bargmann et al., 2011; Faria et al., 2014), Antarctica, a vertical girdle-type fabric is observed, which characterizes regions with a component of horizontal tension associated with an asymmetry in the two lateral extensions.

The fabric depth profile along ice cores generally follows a continuous trend. Departure from this trend can be attributed to dynamic recrystallization processes such as those observed at the deepest part of the GRIP ice core (Thorsteinsson et al., 1997) and the GISP2 ice core (Gow et al., 1997), as well as at various depths in the Siple Dome ice core, Antarctica (Diprinzio et al., 2005). They may also be attributed to a positive feedback between variations in ice viscosity, which can be related to variations in dust content and/or initial fabric at deposition, and the impact of a shear stress component that is increasing with depth. This was observed at EPICA Dome $\mathrm{C}$ at $1750 \mathrm{~m}$ depth during termination 2 (Durand et al., 2007) and for the Holocene-Wisconsin transition at Dye 3 (Thorsteinsson et al., 1999) and Talos Dome (Montagnat et al., 2012).

The $2540 \mathrm{~m}$ long NEEM ice core was drilled during field seasons 2008 to $2012\left(77.45^{\circ} \mathrm{N}, 51.06^{\circ} \mathrm{W}\right.$, surface elevation $2450 \mathrm{~m}$, mean annual temperature $-29^{\circ} \mathrm{C}$, accumulation of $0.22 \mathrm{~m}$ ice equivalent $\mathrm{yr}^{-1}$ ) (Dahl-Jensen et al., 2013). The drill site (Fig.1) is located downstream of the ice ridge that runs NNW from the summit of the Greenland ice sheet where the GRIP core was extracted (Dansgaard et al., 1993). Along this ridge towards Camp Century, the NGRIP ice core site is located $325 \mathrm{~km}$ to the NW of GRIP, and $365 \mathrm{~km}$ upstream from NEEM (Dahl-Jensen et al., 2002).

The GRIP, NGRIP, and NEEM ice cores were drilled with the major objective of retrieving climatic information from the last interglacial period, the Eemian (between 130000 and $115000 \mathrm{yr}$ ago), during which NEEM surface temperature was estimated to be about $8 \pm 4^{\circ}$ warmer than today (DahlJensen et al., 2013). Stratigraphic disturbance in the bottom of the GRIP ice core prevented the core from revealing climatic information from this period of time (Chappellaz et al., 1997; Suwa et al., 2006). Layering in the deepest $10 \%$ of the core was shown to be inclined by about $20^{\circ}$, and discontinuous layering as well as small-scale folds have been observed



Figure 1. Greenland Ice Sheet surface elevation (Bamber et al., 2013) and location of the GRIP, GISP2, NGRIP, NEEM and Camp Century drilling sites. Contours are every $50 \mathrm{~m}$. A flow line following the greatest slope along the NNW ridge is shown in blue.

(Alley et al., 1995). The NGRIP core proved to be located on a zone of high heat flow from the underlying crust (DahlJensen et al., 2003). This heat melted the basal ice, eliminating the oldest ice layers, and only the last few millennia of the Eemian could be retrieved (Cuffey, 2004). The high melting at the bottom of the NGRIP core significantly reduced the thinning of deep ice layers, allowing an annual resolution of the glacial-onset record (Svensson et al., 2011).

The upper $1419 \mathrm{~m}$ of the NEEM ice core covers the current interglacial, the Holocene, and the glacial ice is found down to $2206.7 \mathrm{~m}$ depth. Below this, the ice is disturbed and folded to some degree, but the Eemian record could be reconstructed from folded ice using globally homogeneous parameters known from other dated Greenland and Antarctic ice core records (Dahl-Jensen et al., 2013).

\section{Fabric measurements}

The NEEM fabric data were measured in the field, at the NEEM camp, during field seasons 2009 to 2011, from $33 \mathrm{~m}$ to $2461 \mathrm{~m}$ depth at a $10 \mathrm{~m}$ resolution. First, vertical thin ice core sections were produced directly from the extracted cores, except for the brittle ice zone that was drilled in 2009 but studied at the NEEM site in 2010. The brittle ice zone, extending from about $600 \mathrm{~m}$ to $1300 \mathrm{~m}$ depth, corresponds to ice highly affected structurally by the pressure from air bubbles that have not yet turned into clathrates (Lipenkov, 2000; 
Kipfstuhl et al., 2001). A 1-year period is considered necessary to relax these constrains enough for ice to be processed.

The raw fabric data were obtained using two automatic ice texture analyzers (AITA) (Russell-Head and Wilson, 2001) of similar versions. The AITA provides $c$ axis orientations from thin sections of dimensions up to $12 \times 12 \mathrm{~cm}^{2}$, at a resolution of $43 \mu \mathrm{m}$ length for the older version (season 2009), and of $20 \mu \mathrm{m}$ length for the more recent one (season 2010). Orientation measurements are provided together with a quality factor that enables the elimination of sample areas with too much uncertainty, such as grain boundaries (Peternell et al., 2011). A threshold value for this quality factor was chosen at $70 \%$ for all the thin sections studied.

The $c$ axis orientation $c^{k}$ is defined by two angles: the colatitude $\theta_{k} \in[0, \pi / 2]$ (or tilt angle) and the longitude $\varphi_{k} \in$ $[0,2 \pi]$ given in the local reference frame, $\boldsymbol{R}$, with the third axis perpendicular to the thin section plan. The expression of $c^{k}$ in this reference frame is

$c^{k}=\left(\cos \varphi_{k} \sin \theta_{k}, \sin \varphi_{k} \sin \theta_{k}, \cos \theta_{k}\right)$

The orientation data can further be represented in pole figures, which are stereographic projections of the $c$ axis distributions (Fig. 3).

Following a well-known procedure (Wallbrecher, 1986; Thorsteinsson et al., 1997; Durand et al., 2006a) we represent the fabric using the second-order orientation tensor $\mathbf{a}^{(2)}$ and its eigenvalues $a_{i}^{(2)}(i=1,2,3)$. The eigenvalues of $\mathbf{a}^{(2)}$ can be seen as the lengths of the axes of the ellipsoid that best fits the density distribution of grain orientations. The eigenvectors give the directions of the axes of the ellipsoid.

The three eigenvalues $a_{1}^{(2)}, a_{2}^{(2)}$ and $a_{3}^{(2)}$ follow the relations

$a_{1}^{(2)}+a_{2}^{(2)}+a_{3}^{(2)}=1$

$0 \leq a_{3}^{(2)} \leq a_{2}^{(2)} \leq a_{1}^{(2)} \leq 1$.

For an ideal isotropic fabric, $a_{1}^{(2)}=a_{2}^{(2)}=a_{3}^{(2)}=1 / 3$, and when the fabric is transversely isotropic, two of the eigenvalues are equal:

$a_{2}^{(2)} \approx a_{3}^{(2)}<1 / 3$ for a single-maximum fabric,

$a_{1}^{(2)} \approx a_{2}^{(2)}>1 / 3$ for a perfect vertical girdle fabric.

From a similar treatment of fabric data from the Talos Dome ice core (Antarctica), Montagnat et al. (2012) showed that the error made on the eigenvalues of $\mathbf{a}^{(2)}$, associated with the analyzer measurement by itself, is very small. In particular, it is negligible compared to that induced by a sampling on a limited number of grains. This last error was estimated by Durand et al. (2006a) using a 3-D Potts model to evaluate the influence of the undersampling of a sample of 10000 grains of the same size, on the evaluation of the orientation tensor eigenvalues. They obtained a relation between the error $\left(E_{\mathrm{r}}\right)$,

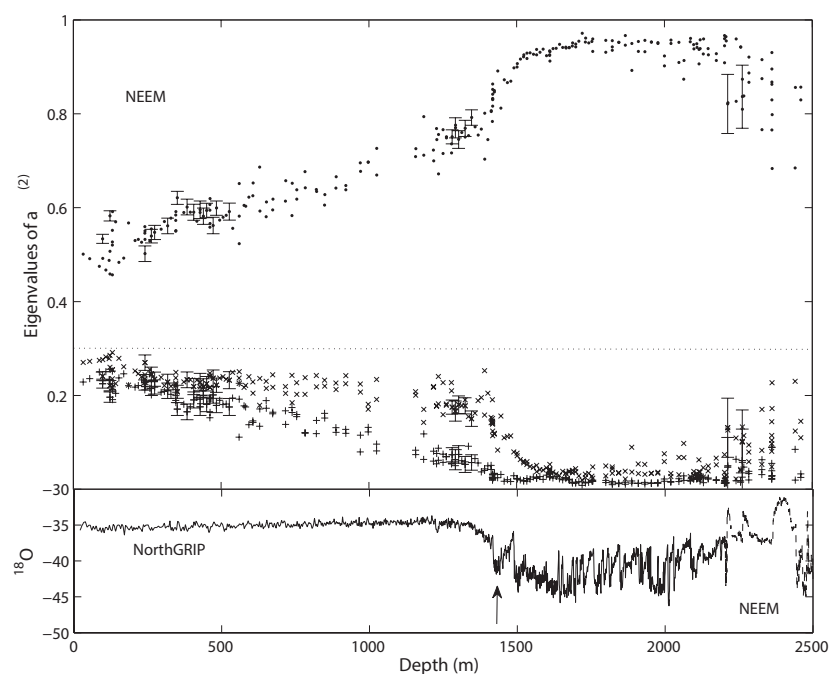

Figure 2. Top: fabric profile along the NEEM ice core, represented by the eigenvalues of the orientation tensor $\mathbf{a}^{(2)}$ (dot: $a_{1}^{(2)}$, cross: $a_{2}^{(2)}$, plus: $\left.a_{3}^{(2)}\right)$. Error bars correspond to a $\pm 1 E_{\mathrm{r}}$ confidence interval (see text). Bottom: evolution of the climate proxy isotope $\delta^{18} \mathrm{O}$ from the NGRIP ice core transferred to the NEEM depth scale (Rasmussen et al., 2013) for the upper $2200 \mathrm{~m}$, and from the NEEM ice core below $2200 \mathrm{~m}$ depth (dashed line) (Dahl-Jensen et al., 2013). The NEEM isotope data are not available yet, but the overall features are very similar to those of NGRIP. The arrow represents the depth of the glacial termination at NEEM, $1419 \mathrm{~m}$.

the number of grains in the thin section, $N_{\mathrm{g}}$, and the eigenvalues. Although the grain size evolution along the NEEM core is not presented here, a few grain size data were measured and used to provide the error on the eigenvalues presented in the Fig. 2.

\section{Results}

\subsection{Fabric evolution with depth}

Fabric as a function of depth is presented in Fig. 2, using the three eigenvalues of the orientation tensor $\mathbf{a}^{(2)}$, together with the $\delta^{18} \mathrm{O}$ record of NGRIP transferred to the NEEM depth scale using the (Rasmussen et al., 2013) chronology. This record can be used as a climate proxy, as it is known to show the same climate variability as that of NEEM (the NEEM $\delta^{18} \mathrm{O}$ record is not available yet). The error bars correspond to the standard deviation due to the limited number of grains on the thin section, as explain in Sect. 2. The level of uncertainty induced by the undersampling over a limited number of grains appears to be of the same order of magnitude as the variability with depth.

Figure 3 provides a direct view of the microstructure evolution (grain size and shape) along the core, together with a horizontal pole figure representation of the fabric evolution, from selected depths. 


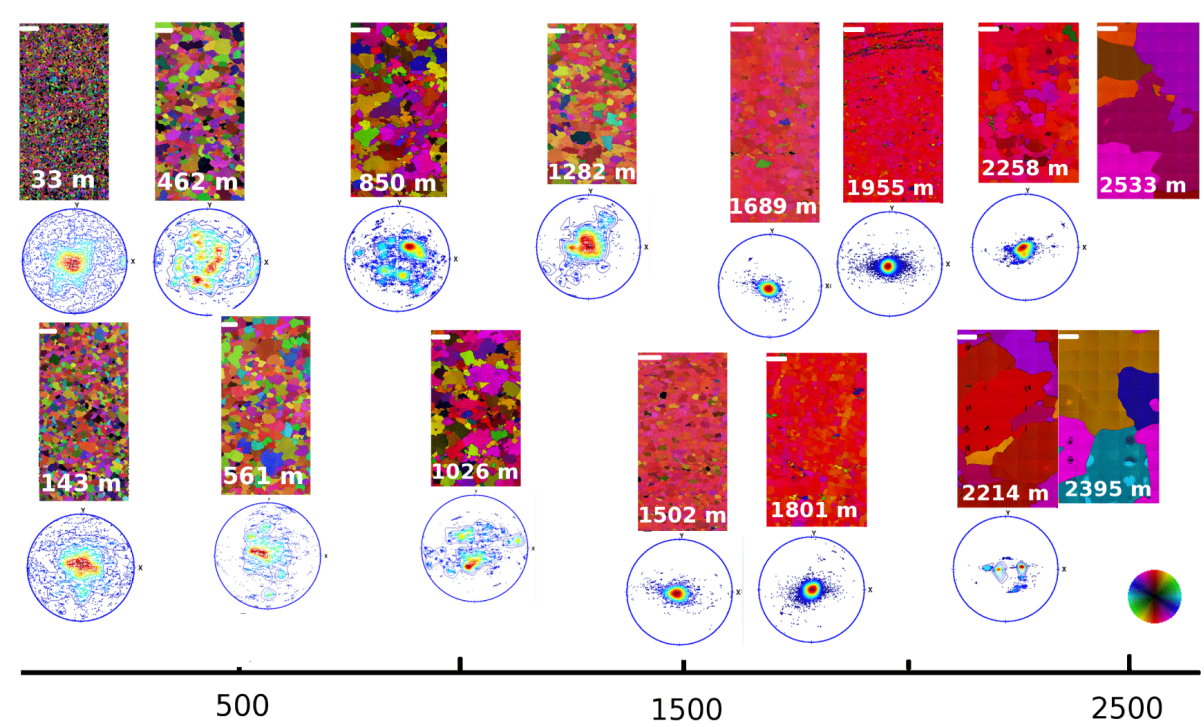

Figure 3. Evolution with depth of the microstructures observed in $c$ axis orientation color scale (see color wheel on the bottom right), and of the fabric represented by pole figures. The thin sections of about $8 \times 11 \mathrm{~cm}^{2}$ in dimension are vertical (i.e. in the coring direction). Length scale (white line) is $10 \mathrm{~mm}$. The pole figures are represented with the vertical axis (core axis) perpendicular to the plane of the figure.

Although grains are very small at the top of the core, the fabric is not isotropic, as shown by the slight clustering $\left(a_{1}^{(2)} \geq 0.45\right)$. Grain size increases and fabric progressively clusters with depth until close to the HW climatic transition, where grain size is strongly reduced and fabric abruptly strengthens to a strong single maximum. The eigenvalue variability with depth is quite small just below the transition, until about $1800 \mathrm{~m}$ depth, where this variability starts increasing. The bottom part of the core (below about $2200 \mathrm{~m}$ ) is characterized by layers of large interlocked grains with multi-clustered fabric alternating with layers of smaller grains with highly clustered single-maximum fabric.

\subsection{Comparison with the GRIP and NGRIP ice cores}

Fabric along the NEEM ice core is compared to that along the GRIP ice core (Thorsteinsson et al., 1997; Svensson et al., 2009) (Fig. 4) and the NGRIP ice core (Wang et al., 2002) (Fig. 5, Svensson et al., 2009).

The GRIP ice core was drilled at the present-day summit of the ice sheet, NGRIP was drilled about $325 \mathrm{~km}$ away along the NNW ridge, and the NEEM ice core, located $365 \mathrm{~km}$ further, is close to a divergence departure point of the ridge line (Fig. 1). The main characteristics for the three coring sites are given in Table 1.

The shape and intensity of the fabrics in ice cores mainly depends on the strain history. Therefore, the interpretation of the fabric differences between the cores requires estimates of the strain-rate histories experienced by the ice. Here we provide estimates of the current strain rates at the core locations as a function of depth. Our main goal is to estimate the

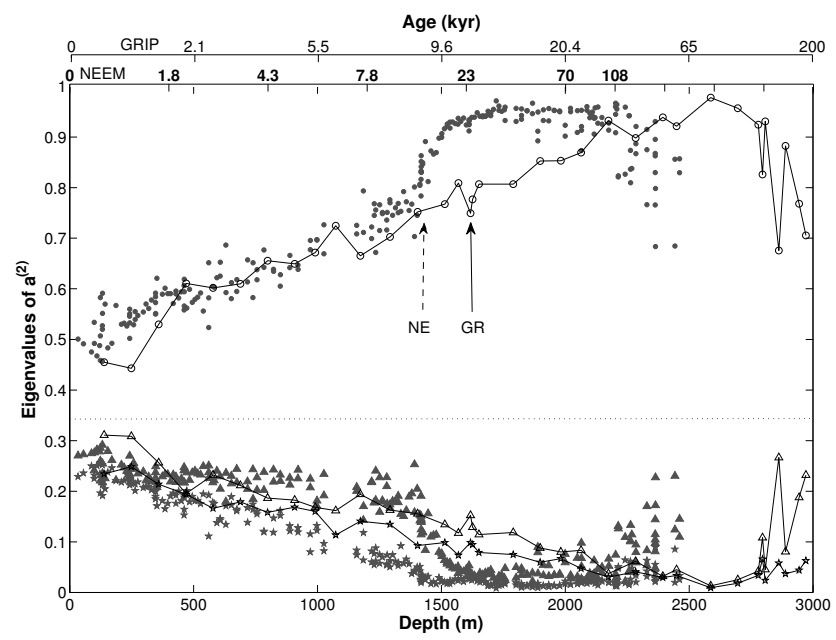

Figure 4. Comparison between the fabric profiles along the NEEM ice core (filled symbols) and the GRIP ice core (open symbols) (dot: $a_{1}^{(2)}$, triangle: $a_{2}^{(2)}$, star: $a_{3}^{(2)}$ ) (Thorsteinsson et al., 1997; Svensson et al., 2009). Arrows indicate the HW climatic transition (NE: NEEM, GR: GRIP). Top axes: approximate age scales for both cores.

depth at which vertical shear strain rates become dominant over vertical compressive strain rates.

A rough first estimate of the mean vertical strain rate $D_{z z}$ can be obtained from the ratio between the annual ice accumulation $a$ and the ice thickness $H$ (Table 1). This ratio is of a similar order of magnitude at the three sites, between 6 and $9 \times 10^{-5} \mathrm{a}^{-1}$. Furthermore, surface vertical strain rates were measured directly using a phase sensitive radar system near the GRIP and NEEM sites (Gillet-Chaulet et al., 2011), 


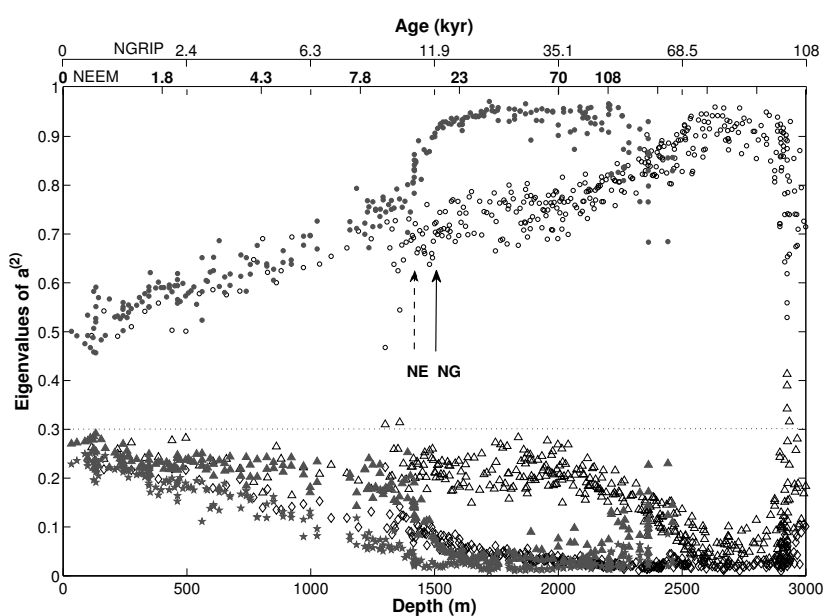

Figure 5. Comparison between the fabric profiles along the NEEM ice core (filled symbols) and the NGRIP ice core (open symbols) (dot: $a_{1}^{(2)}$, triangle: $a_{2}^{(2)}$, star: $a_{3}^{(2)}$ ) (Wang et al., 2002; Svensson et al., 2009). Arrows indicate the HW climatic transition (NE: NEEM, NG: NGRIP). Top axes: approximate age scales for both cores.

Table 1. Ice thickness $(H)$, annual accumulation $(a)$, average annual temperature $\left(T_{\mathrm{yr}}\right)$, ratio $a / H$ and surface slope magnitude $(\mathrm{d} s / \mathrm{d} x)$ in GRIP, NGRIP and NEEM ice cores (references are given in the text).

\begin{tabular}{lrrrrr}
\hline & $H$ & $a$ & $T_{\mathrm{yr}}$ & $a / H$ & $\mathrm{~d} s / \mathrm{d} x$ \\
\cline { 2 - 6 } & $\mathrm{m}$ & $\begin{array}{c}\text { ice eq. } \\
\mathrm{m} \mathrm{a}^{-1}\end{array}$ & ${ }^{\circ} \mathrm{C}$ & $10^{-5} \mathrm{a}^{-1}$ & $\mathrm{~m} \mathrm{~km}^{-1}$ \\
\hline GRIP & 3027 & 0.24 & -32 & 7.9 & 0.53 \\
NGRIP & 3085 & 0.19 & -32.5 & 6.1 & 0.90 \\
NEEM & 2540 & 0.22 & -29 & 8.7 & 1.83 \\
\hline
\end{tabular}

average values are $9.5 \times 10^{-5} \mathrm{a}^{-1}$ and $11.5 \times 10^{-5} \mathrm{a}^{-1}$, respectively. Hvidberg and Keller (2002) used surface velocity measurements in the NGRIP area to calculate surface strain rates in the direction transverse to the ice-divide ridge and obtained $7.4 \times 10^{-5} \mathrm{a}^{-1}$. For the evolution with depth, we assume that vertical strain rates along the cores follow a Dansgaard-Johnsen profile (Dansgaard and Johnsen, 1969), that is, the strain rate is constant in the upper two-thirds of the ice thickness and then linearly decreases to zero at the bottom. Because the three cores have similar conditions, only one profile of the vertical strain rate, representative of the three cores, is shown in Fig. 6, where the surface vertical strain rate is chosen as $10 \pm 1 \times 10^{-5} \mathrm{a}^{-1}$ and the ice thickness ranges from $2540 \mathrm{~m}$ (NEEM thickness) to $3085 \mathrm{~m}$ (NGRIP thickness). We do not estimate here the two other longitudinal components of the strain-rate tensor (horizontal components) as they are difficult to quantify from topographic considerations. However, as NEEM and NGRIP are located

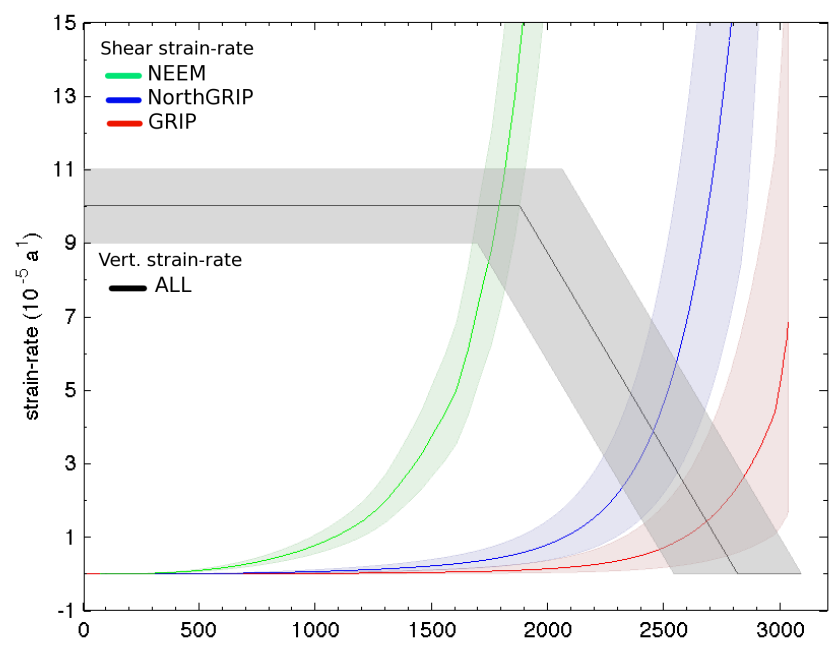

Figure 6. Evolution of the shear strain rates, $D_{x z}$, along the GRIP (red), NGRIP (blue) and NEEM (green) ice cores with error bars. The black line represents the estimated evolution of the vertical strain rate $D_{z z}$, which is basically the same for all three cores regarding the error bars.

on the ridge, we can anticipate an asymmetry between the horizontal strain rates along and perpendicular to the ridge.

The vertical shear stress along the cores $S_{x z}$, in a local reference frame where $x$ is aligned with the surface slope direction, is estimated using the shallow ice approximation (Greve and Blatter, 2009):

$S_{x z}=\rho g z \mathrm{~d} s / \mathrm{d} x$,

with $\rho$ being the ice density, $g$ the standard gravity and $z$ the depth from the surface. Surface slope $\mathrm{d} s / \mathrm{d} x$ is given in Table 1. The shear strain rate $D_{x z}$ is then estimated using Glen's flow law with a stress exponent $n=3$ (Glen, 1955):

$D_{x z}=A(T) S_{x z}^{3}$.

The rate parameter $A(T)$ depends on temperature $T$ following an Arrhenius law. Estimates of the shear strain rate along each core, assuming an uncertainty on the surface slope of $\pm 0.2 \mathrm{~m} \mathrm{~km}^{-1}$, are shown in Fig. 6 .

Shear strain rates equals the vertical strain rates at $\sim 1650 \mathrm{~m}$ at NEEM $(65 \%$ of $H), \sim 2250 \mathrm{~m}$ at NGRIP $(73 \%$ of $H$ ) and $\sim 2400 \mathrm{~m}$ at GRIP (79\% of $H$ ). These estimates of the strain rates along the cores do not take into account possible effects of the ice mechanical anisotropy induced by the fabric development or change in viscosity related with impurity content. Furthermore, the ice in the cores may have been deposited few kilometers to tens of kilometers upstream of the core locations, especially for NGRIP and NEEM (DahlJensen et al., 2013), and then may have experienced a more complex strain-rate history than what is reflected by our estimates. 


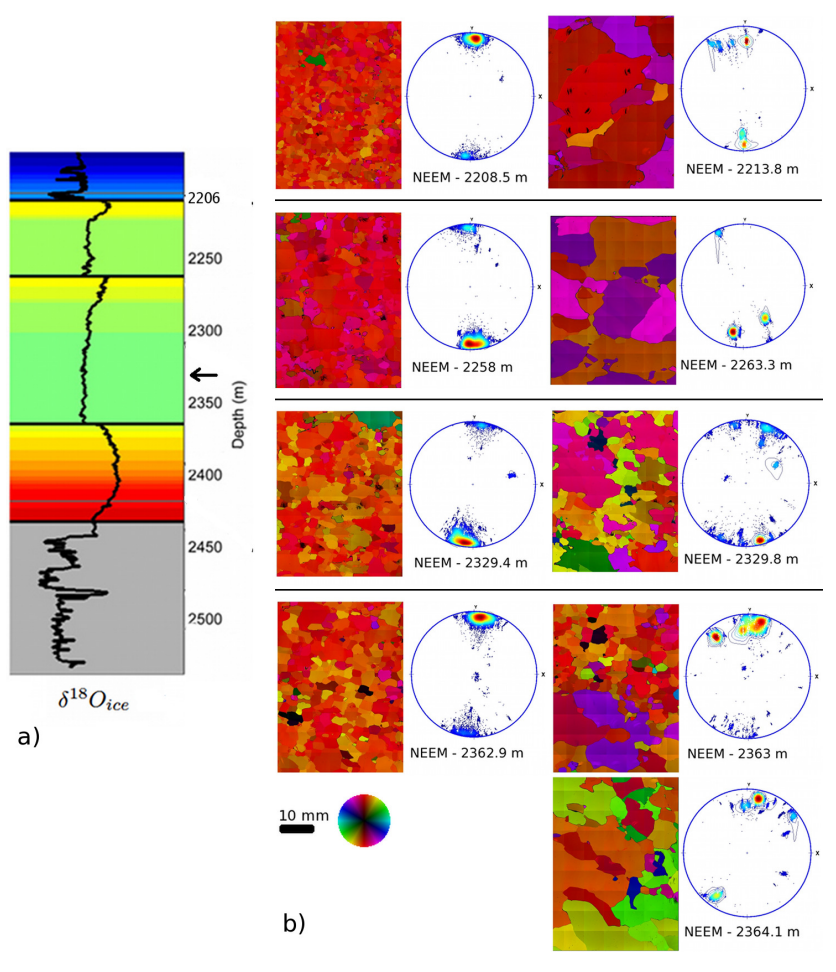

Figure 7. Abrupt variations of fabrics and microstructures around the discontinuities observed in the $\delta^{18} \mathrm{O}_{\text {ice }}$ signal (a) (Dahl-Jensen et al., 2013). Different colors along the stable isotope record highlight the disturbed sections. The reconstructed age-scale corresponds to a continuous color scale. Microstructure and fabric data (b) were chosen on each side of the various discontinuities, but also to reveal other discontinuities (see text). The length scale is the same for all microstructure images (black line). The orientation color scale is given by the color wheel. The pole figures are plotted with the vertical axis (core axis) vertically in the plane of the figure.

\subsection{Disturbed layers in the deepest part of the core}

Dahl-Jensen et al. (2013) reconstructed the stratigraphy of the bottom part of the NEEM core from folded ice layers. Stratigraphic disruptions were identified from discontinuities of the $\delta^{18} \mathrm{O}_{\text {ice }}$ isotope and gas records measured in ice at several depths: $2209.60 \mathrm{~m}, 2262.15 \mathrm{~m}, 2364.45 \mathrm{~m}$ and $2432.19 \mathrm{~m}$. These discontinuities were confirmed by $\mathrm{N}_{2} \mathrm{O}$, $\delta^{15} \mathrm{~N}$ and total air content measurements in the ice below $2200 \mathrm{~m}$ depth.

The existence of disturbed layers is also confirmed in highresolution fabric and microstructure data. Figure 7 represents the NEEM stable water isotope record with emphasis on the discontinuities, together with microstructures and vertical fabric pole figures from around these discontinuities.

Accurate fabric measurements between 2200 and $2400 \mathrm{~m}$ depth reveal several abrupt transitions from "regular" grain size and "single maximum type" fabric to large grain size and multi-clustered fabric, just in the vicinity of the $\delta^{18} \mathrm{O}_{\text {ice }}$ discontinuities (Fig. 7). These transitions were found between
2208 and $2214 \mathrm{~m}, 2258$ and $2263 \mathrm{~m}$, and between 2362.9 and $2363 \mathrm{~m}$ depth, where the discontinuity can be captured within a single $10 \mathrm{~cm}$ thin section. Data measured at $2214 \mathrm{~m}$ depth is very similar to that measured at $2263 \mathrm{~m}$, and measurement at $2258 \mathrm{~m}$ is very close to what is observed at $2362 \mathrm{~m}$ depth (with a slight tilt in the fabric, which could have been introduced during sample preparation). The abrupt transition observed in texture between $2329.4 \mathrm{~m}$ and $2329.8 \mathrm{~m}$ depth does not correspond to any discontinuities in the stable isotope signal.

In order to provide folding between layers, a shear strain should be superimposed on the axial strain, and some irregularities in the viscosity between layers should exist (Gow and Williamson, 1976; Alley et al., 1997). Such irregularities, from microstructure and fabric observations, appear here at a small scale, and could be inherited from initial variability (conjugate effect of dust content, initial fabric and strain history). Below each abrupt transition, the fabric and microstructures measured reveal the occurrence of dynamic recrystallization (DRX) because of the large interlocking grains and loose or multiple maxima fabrics (Thorsteinsson et al., 1997; de la Chapelle et al., 1998; Duval et al., 2000) (Fig. 7). This would be very coherent with the analyses of Wilson et al. (2003) whereby folding is based on experimental observation and who suggested that, although an initial perturbation in local viscosity is required, DRX could enhance folding by increasing local strain rate in the folded area.

\section{Discussion}

The fabric profile along the NEEM ice core presents the classical feature of a progressive $c$ axis orientation strengthening with depth toward a single maximum. This feature is typical of a deformation pattern mostly driven by vertical compression and simple shearing that is observed in many ice cores retrieved from ice divides, such as GRIP, EPICA Dome C, and Talos Dome ice cores.

The initial fabric measured in the firn (from $33 \mathrm{~m}$ depth downwards) is not isotropic. This observation supports those from the EPICA Dome C ice core (Durand et al., 2009), the GRIP and NGRIP ice cores (Svensson et al., 2009) and the Talos Dome ice core (Montagnat et al., 2012), and contradicts the results obtained by Lomonaco et al. (2011) from sparse fabric measurements performed in the top $120 \mathrm{~m}$ of a firn core drilled at Summit, with the electron backscattering technique. The slightly clustered fabrics measured in the NEEM firn, which can not be explained by the level of strain reached at these depths (Montagnat et al., 2012), may be associated with fabric evolution mechanisms that could occur during firnification, in the upper hundred meters of the ice sheet. Further studies of fabric evolution in snow and firn are therefore necessary to better understand these observations, 
in particular to evaluate the possibility of a link between initial fabric and climatic conditions (Riche et al., 2012).

Similar to the observations made along most of the deep Greenland and Antarctic ice cores, the $c$ axis orientation strengthening along the NEEM core is far from being monotonous. Indeed, a sharp increase in the strengthening rate is concomitant with the climatic transition between the Holocene and the Wisconsin periods. This transition is also characterized by a strong variation in the dust content, as observed along various Greenland ice cores (Steffensen et al., 2008). Therefore, following Paterson (1991) we could attribute the change in strengthening rate to some feedback between changes in ice viscosity from Wisconsin to Holocene ice, and the impact of a shear component of stress. The influence of a non-negligible shear component of stress is necessary to explain the strong $c$ axis clustering observed in the range of 1800-2000 $\mathrm{m}$ depth (Azuma and Higashi, 1985; Paterson, 1991; Alley, 1992; Thorsteinsson et al., 1997).

This hypothesis is strengthened by the comparison performed in Sect. 3.2 between the three cores, GRIP, NGRIP and NEEM in terms of fabric and strain rate. The three ice cores are located along the same ridge, departing from a dome configuration at the summit of the ice sheet, Fig. 1.

The fabric profile along the GRIP ice core is the most monotonous (Fig. 4), with no obvious abrupt changes at the onset of the Holocene, although a strong variation in the grain size evolution was measured at this transition (Thorsteinsson et al., 1997). GRIP is located near the dome where uniaxial compression is expected to dominate (vertical compression and uniform extension in the horizontal directions). Thorsteinsson et al. (1997) assumed an effect of simple shear deformation between 2850 and $2950 \mathrm{~m}$ depth where the fabric becomes highly clustered. The highly clustered fabrics alternate with more open ones from about $2800 \mathrm{~m}$ depth, together with a grain size increase explained by the influence of dynamic recrystallization mechanisms (Thorsteinsson et al., 1997). From the estimation of strain-rate evolution with depth along this core (Sect. 3.2), vertical strain rate only becomes dominant after about $2400 \mathrm{~m}$ depth, far below the climatic transition $(\sim 1620 \mathrm{~m})$, where we observe no abrupt fabric transition.

At NGRIP, we observe a progressive strengthening of the fabric below about $2300 \mathrm{~m}$ depth, close to the depth where we estimate the shear strain rate to become dominant (Fig. 6). Similar to what is found for GRIP, the climatic transition is located much higher in the core ( $\sim 1500 \mathrm{~m}$ depth) and it is not coincident with a change in the fabric strengthening. Whereas at NEEM, the shear strain rate becomes dominant at an estimated depth of about $1650 \mathrm{~m}$, which is very close to the climatic transition $(\sim 1420 \mathrm{~m})$. From this comparison, we can confirm that a change in ice viscosity (due to a climatic transition) should be associated with a dominant shear strain state in order to induce a sharp strengthening of fabric. The origin of the change in ice viscosity with the HW transition could not be identified here, but could likely be due to a variation in initial fabric at or close to deposition, and/or the variation of dust content.

The strain-rate estimation presented in Sect. 3.2 does not consider strain state in the horizontal dimensions, the lateral extension, as it would be more difficult to estimate without precise topographic records. The location along a ridge can induce an evolution of the fabric toward a girdle type, which characterizes pure shear deformation with a dissymmetry of the horizontal extension (Lipenkov et al., 1989; Bargmann et al., 2011; Faria et al., 2014). Along the NGRIP ice core, a mild vertical girdle-type pattern is evidenced by the increase of the $a_{2}^{(2)}$ eigenvalue compared to $a_{3}^{(2)}$, from $500 \mathrm{~m}$ depth down to about $2500 \mathrm{~m}$. Below this depth, the fabric progressively clusters again toward a single maximum by the bottom of the core (Fig. 5). A vertical girdle pattern is also observed along the NEEM core but less pronounced, and only down to the HW transition. Such a difference could likely be attributed to a higher asymmetry of the lateral extension at NGRIP compared to NEEM, where the ridge is sharper (Fig. 1). However, this lateral extension effect on fabric could also be counteracted, at NEEM, by the dominating shear strain state below $1650 \mathrm{~m}$ depth.

Fabric and microstructure signals in the bottom part of the NEEM core present a high variability, in the area where evidence of folding was given by Dahl-Jensen et al. (2013) (Sect. 3.3). The abrupt variations in the microstructure and fabric signals are in agreement with the stratigraphical reconstruction performed by Dahl-Jensen et al. (2013).

Such a folding configuration, which is typically observed at the base of glaciers and ice sheets where temperature and/or stress gradients are increased (Gow and Williamson, 1976; Herron and Langway, 1982; Budd and Jacka, 1989; Thorsteinsson et al., 1997) has been observed at the base of the GRIP ice core, but not at the base of the NGRIP core. The comparison between the three cores therefore highlights the influence of the basal temperature and the shear component of stress on the thinning and the folding of the bottom layers.

\section{Conclusions}

This paper presents the overall features of the fabric data measured in the field, every $10 \mathrm{~m}$ along the NEEM ice core, Greenland. The main observations are the following:

i. Similar to what was observed along other deep ice cores, the initial fabric, measured from $33 \mathrm{~m}$ depth downward, is not isotropic and may therefore be associated with fabric evolution during firnification.

ii. Down to about $1500 \mathrm{~m}$ depth, the fabric evolves toward a single maximum, with a slight girdle tendency. This is coherent with the position along a ridge, characterized by a vertical compression and a slight asymmetry in the horizontal extension. 
iii. A sharp fabric strengthening is measured at the Holocene-Wisconsin transition, with a maximum reached at about $1800 \mathrm{~m}$ depth, and maintained down to $2300 \mathrm{~m}$ depth. From the comparison with the GRIP and NGRIP ice cores extracted along the same ridge, we associate this strengthening to the viscosity change due to climatic transition, together with a dominant shear strain state. This is coherent with the feedback described by Paterson (1991) between ice viscosity changes, and the impact of shear on the ice flow.

iv. Deeper in the ice core, the local variations of fabric and grain size support the folding hypothesis of Dahl-Jensen et al. (2013) and the suggested layering reconstruction.

v. The first-order comparison made with the GRIP and NGRIP ice cores could therefore be helpful to constrain ice flow modeling along the ridge from GRIP to NEEM and onwards to Camp Century.

Acknowledgements. This work is a contribution to the NEEM ice core project that is directed and organized by the Centre of Ice and Climate at the Niels Bohr Institute and US NSF, Office of Polar Programs. It is supported by funding agencies and institutions in Belgium (FNRS-CFB and FWO), Canada (NRCan/GSC), China (CAS), Denmark (FIST), France (IPEV, CNRS/INSU, CEA and ANR), Germany (AWI), Iceland (RannIs), Japan (NIPR), South Korea (KOPRI), the Netherlands (NWO/ ALW), Sweden (VR), Switzerland (SNF), the United Kingdom (NERC) and the USA (US NSF, Office of Polar Programs) and the EU Seventh Framework programmes Past4Future and WaterundertheIce. IW acknowledges financial support by the Helmholtz Association (VH-NG-802). MM and FGC are part of Labex OSUG@2020 (ANR10 LABX56). DS was funded by the Japanese Society for the Promotion of Science, and he was supported by a "Ymer-80 stipender för polarforskning" (Sweden) during his stay at NEEM.

Edited by: J. Moore

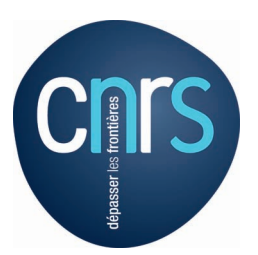

The publication of this article is financed by CNRS-INSU.

\section{References}

Alley, R. B.: Fabrics in polar ice sheets - Development and prediction, Science, 240, 493-495, 1988.

Alley, R. B.: Flow-law hypotheses for ice-sheet modeling, J. Glaciol., 38, 245-255, 1992.

Alley, R. B., Gow, A. J., Johnsen, S. J., Kipfstuhl, J., Meese, D. A., and Thorsteinsson, T.: Comparison of deep ice cores, Nature, 373, 393-394, doi:10.1038/373393b0, 1995.
Alley, R. B., Gow, A. J., Meese, D. A., Ftizpatrick, J. J., Waddington, E. D., and Bolzan, J. F.: Grain-scale processes, folding, and stratigraphic disturbance in the GISP2 ice core, J. Geophys. Res., 102, 26819-26830, 1997.

Azuma, N. and Higashi, A.: Formation processes of ice fabric pattern in ice sheets, Ann. Glaciol., 6, 130-134, 1985.

Azuma, N., Wang, Y., Mori, K., Narita, H., Hondoh, T., Shoji, H., and Watanabe, O.: Textures and fabrics in the Dome F (Antarctica) ice core, Ann. Glaciol., 29, 163-168, 1999.

Bamber, J. L., Griggs, J. A., Hurkmans, R. T. W. L., Dowdeswell, J. A., Gogineni, S. P., Howat, I., Mouginot, J., Paden, J., Palmer, S., Rignot, E., and Steinhage, D.: A new bed elevation dataset for Greenland, The Cryosphere, 7, 499-510, doi:10.5194/tc-7499-2013, 2013.

Bargmann, S., Seddik, H., and Greve, R.: Computational modeling of flow-induced anisotropy of polar ice for the EDML deep drilling site, Antarctica: the effect of rotation recrystallization and grain boundary migration, Int. J. Numer. Anal. Met.., 36, 892-917, doi:10.1002/nag.1034, 2011.

Budd, W. and Jacka, T.: A review of ice rheology for ice sheet modelling, Cold Reg. Sci. Technol., 16, 107-144, 1989.

Chappellaz, J., Blunier, T., Kints, S., Dallenbach, A., Barnola, J.-M., Schwander, J., Raynaud, D., and Stauffer, B.: Changes in the atmospheric $\mathrm{CH}_{4}$ gradient between Greenland and Antarctica during the Holocene, J. Geophys. Res.-Atmos., 102, 15987-15997, doi:10.1029/97JD01017, 1997.

Cuffey, K. M.: Palaeoclimate: Into an ice age, Nature, 431, 133 134, 2004.

Dahl-Jensen, D., Gundestrup, N., Miller, H., Watanabe, O., Johnsen, S. J., Steffensen, J. P., Clausen, H. B., Svensson, A., and Larsen, L. B.: The NorthGRIP deep drilling programme., Ann. Glaciol., 35, 1-4, 2002.

Dahl-Jensen, D., Gundestrup, N., Gorgineni, S. P., and Miller, H.: Basal melt at NorthGRIP modeled from borehole, ice-core and radio-echo sounder observations, Ann. Glaciol., 37, 207-212, 2003.

Dahl-Jensen, D., Albert, M. R., Aldahan, A., Azuma, N., BalslevClausen, D., Baumgartner, M., Berggren, A.-M., Bigler, M., Binder, T., Blunier, T., Bourgeois, J. C., Brook, E. J., Buchardt, S. L., Buizert, C., Capron, E., Chappellaz, J., Chung, J., Clausen, H. B., Cvijanovic, I., Davies, S. M., Ditlevsen, P., Eicher, O., Fischer, H., Fisher, D. A., Fleet, L. G., Gfeller, G., Gkinis, V., Gogineni, S., Goto-Azuma, K., Grinsted, A., Gudlaugsdottir, H., Guillevic, M., Hansen, S. B., Hansson, M., Hirabayashi, M., Hong, S., Hur, S. D., Huybrechts, P., Hvidberg, C. S., Iizuka, Y., Jenk, T., Johnsen, S. J., Jones, T. R., Jouzel, J., Karlsson, N. B., Kawamura, K., Keegan, K., Kettner, E., Kipfstuhl, S., Kjær, H. A., Koutnik, M., Kuramoto, T., Köhler, P., Laepple, T., Landais, A., Langen, P. L., Larsen, L. B., Leuenberger, D., Leuenberger, M., Leuschen, C., J. Li, V. L., Martinerie, P., Maselli, O. J., Masson-Delmotte, V., McConnell, J. R., Miller, H., Mini, O., Miyamoto, A., Montagnat-Rentier, M., Mulvaney, R., Muscheler, R., Orsi, A. J., Paden, J., Panton, C., Pattyn, F., Petit, J.-R., Pol, K., Popp, T., Possnert, G., Prié, F., Prokopiou, M., Quiquet, A., Rasmussen, S. O., Raynaud, D., Ren, J., Reutenauer, C., Ritz, C., Röckmann, T., Rosen, J. L., Rubino, M., Rybak, O., Samyn, D., Sapart, C. J., Schilt, A., Schmidt, A. M. Z., Schwander, J., Schüpbach, S., Seierstad, I., Severinghaus, J. P., Sheldon, S., Simonsen, S. B., Sjolte, J., Solgaard, A. M., Sowers, T., Sper- 
lich, P., Steen-Larsen, H. C., Steffen, K., Steffensen, J. P., Steinhage, D., Stocker, T. F., Stowasser, C., Sturevik, A. S., Sturges, W. T., Sveinbjörnsdottir, A., Svensson, A., Tison, J.-L., Uetake, J., Vallelonga, P., van de Wal, R. S. W., van der Wel, G., Vaughn, B. H., Vinther, B., Waddington, E., Wegner, A., Weikusat, I., White, J. W. C., Wilhelms, F., Winstrup, M., Witrant, E., Wolff, E. W., Xiao, C., and Zheng, J.: Eemian interglacial reconstructed from a Greenland folded ice core, Nature, 493, 489-494, 2013.

Dansgaard, W. and Johnsen, S. J.: A flow model and a time scale for the ice core from Camp Century, Greenland, J. Glaciol., 8, 215-223, 1969.

Dansgaard, W., Johnsen, S. J., Clausen, H. B., Dahl-Jensen, D., Gundestrup, N. S., Hammer, C. U., Hvidberg, C. S., Steffensen, J. P., Sveinbjörnsdottir, A. E., Jouzel, J., and Bond, G.: Evidence for general instability of past climate from a $250 \mathrm{kyr}$ ice-core record, Nature, 364, 218-220, 1993.

de la Chapelle, S., Castelnau, O., Lipenkov, V., and Duval, P.: Dynamic recrystallization and texture development in ice as revealed by the study of deep ice cores in Antarctica and Greenland, J. Geophys. Res., 103, 5091-5105, 1998.

Diprinzio, C. L., Wilen, L. A., Alley, R. B., Fitzpatrick, J. J., Spencer, M. K., and Gow, A. J.: Fabric and texture at Siple Dome, Antarctica, J. Glaciol., 51, 281-290, 2005.

Durand, G., Gagliardini, O., Thorsteinsson, T., Svensson, A., Kipfstuhl, J., and Dahl-Jensen, D.: Ice microstructure and fabric: an up to date approach to measure textures, J. Glaciol., 52, 619-630, 2006a.

Durand, G., Weiss, J., Lipenkov, V., Barnola, J. M., Krinner, G., Parrenin, F., Delmonte, B., Ritz, C., Duval, P., Röthlisberger, R., and Bigler, M.: Effect of impurities on grain growth in cold ice sheets, J. Geophys. Res.-Earth, 111, F01015, doi:10.1029/2005JF000320, 2006b.

Durand, G., Gillet-Chaulet, F., Svensson, A., Gagliardini, O., Kipfstuhl, S., Meyssonnier, J., Parrenin, F., Duval, P., and Dahl-Jensen, D.: Change in ice rheology during climate variations - implications for ice flow modelling and dating of the EPICA Dome C core, Clim. Past, 3, 155-167, doi:10.5194/cp-3-155-2007, 2007.

Durand, G., Svensson, A., Persson, A., Gagliardini, O., GilletChaulet, F., Sjolte, J., Montagnat, M., and Dahl-Jensen, D.: Evolution of the texture along the EPICA Dome C ice core, Supp. Issue Low Temperature, Science, 68, 91-106, 2009.

Duval, P. and Lorius, C.: Crystal size and climatic record down to the last ice age from Antarctic ice, Earth Planet. Sc. Lett., 48, 59-64, 1980.

Duval, P., Arnaud, L., Brissaud, O., Montagnat, M., and de La Chapelle, S.: Deformation and recrystallization processes of ice from polar ice sheets, Ann. Glaciol., 30, 83-87, 2000.

Faria, S. H., Weikusat, I., and Azuma, N.: The microstructure of polar ice. Part I: Highlights from ice core research, J. Struct. Geol., 61, 2-20, doi:10.1016/j.jsg.2013.09.010, 2014.

Gillet-Chaulet, F., Hindmarsh, R. C. A., Corr, H. F. J., King, E. C., and Jenkins, A.: In-situ quantification of ice rheology and direct measurement of the Raymond Effect at Summit, Greenland using a phase-sensitive radar, Geophys. Res. Lett., 38, L24503, doi:10.1029/2011GL049843, 2011.

Glen, J.: The creep of polycrystalline ice, P. R. Soc. London, A228, 519-538, 1955.

Gow, A. J. and Williamson, T. C.: Rheological implications of the internal structure and crystal fabrics of the West Antarctic ice sheet as revealed by deep core drilling at Byrd Station, Geol. Soc. Am. Bull., 87, 1665-1677, 1976.

Gow, A. J., Meese, D. A., Alley, R. B., Fitzpatrick, J. J., Anandakrishnan, S., Woods, G. A., and Elder, B. C.: Physical and structural properties of the Greenland Ice Sheet Project 2 ice core: A review, J. Geophys. Res.-Oceans, 102, 26559-26575, doi:10.1029/97JC00165, 1997.

Greve, R. and Blatter, H.: Dynamics of ice sheets and glaciers, Springer Berlin/Heidelberg, 2009.

Herron, S. L. and Langway, C. C. J.: A comparison of ice fabrics and textures at camp Century, Greenland and Bird Station, Antarctica, Ann. Glaciol., 3, 118-124, 1982.

Hvidberg, C. S. and Keller, K., and Gundestrup, N. S.: Mass balance and ice movement along the north-northwest ridge of the Greenland ice sheet at NorthGRIP, Ann. Glaciol., 35, 521-526, 2002.

Kipfstuhl, S., Pauer, F., Kuhs, W. F., and Shoji, H.: Air bubbles and Clathrate hydrates in the transition zone of the NGRIP Deep Ice Core, Geophys. Res. Lett., 28, 591-594, doi:10.1029/1999GL006094, 2001.

Lipenkov, V.: Air bubbles and air-hydrate crystals in the Vostok ice core, in: Physics of Ice Core Records, edited by: Hondoh, T., 327-358, Hokkaido University Press Sapporo Japan, 2000.

Lipenkov, V. Y., Barkov, N. I., Duval, P., and Pimienta, P.: Crystalline texture of the $2083 \mathrm{~m}$ ice core at Vostok Station, Antarctica, J. Glaciol., 35, 392-398, 1989.

Lomonaco, R., Albert, M., and Baker, I.: Microstructural evolution of fine-grained layers through the firn column at Summit, Greenland, J. Glaciol., 57, 755-762, 2011.

Montagnat, M., Buiron, D., Arnaud, L., Broquet, A., Schlitz, P., Jacob, R., and Kipfstuhl, S.: Measurements and numerical simulation of fabric evolution along the Talos Dome ice core, Antarctica, Earth and Planetary Science Letters, 357-358, 168-178, doi:10.1016/j.epsl.2012.09.025, 2012.

Paterson, W. S. B.: Why ice-age ice is sometimes soft, Cold Reg. Sci. Technol., 20, 75-98, 1991.

Paterson, W. S. B.: The physics of glaciers, Pergamon, Oxford, 1994.

Peternell, M., Russell-Head, D., and Wilson, C.: A technique for recording polycrystalline structure and orientation during in situ deformation cycles of rock analogues using an automated fabric analyser, J. Microsc., 242, 181-188, 2011.

Rasmussen, S. O., Abbott, P. M., Blunier, T., Bourne, A. J., Brook, E., Buchardt, S. L., Buizert, C., Chappellaz, J., Clausen, H. B., Cook, E., Dahl-Jensen, D., Davies, S. M., Guillevic, M., Kipfstuhl, S., Laepple, T., Seierstad, I. K., Severinghaus, J. P., Steffensen, J. P., Stowasser, C., Svensson, A., Vallelonga, P., Vinther, B. M., Wilhelms, F., and Winstrup, M.: A first chronology for the North Greenland Eemian Ice Drilling (NEEM) ice core, Clim. Past, 9, 2713-2730, doi:10.5194/cp-9-2713-2013, 2013.

Riche, F., Schneebeli, M., and Tschanz, S.: Design-based stereology to quantify structural properties of artificial and natural snow using thin sections, Cold Reg. Sci. Technol., 79-80, 6774, doi:10.1016/j.coldregions.2012.03.008, 2012.

Russell-Head, D. S. and Wilson, C. J. L.: Automated fabric analyser system for quartz and ice, J. Glaciol., 24, 117-130, 2001.

Steffensen, J. P., Andersen, K. K., Bigler, M., Clausen, H. B., Dahl-Jensen, D., Fischer, H., Goto-Azuma, K., Hansson, M., Johnsen, S. J., Jouzel, J., Masson-Delmotte, V., Popp, T., Ras- 
mussen, S. O., Röthlisberger, R., Ruth, U., Stauffer, B., SiggaardAndersen, M.-L., Sveinbjörnsdóttir, Á. E., Svensson, A., and White, J. W. C.: High-Resolution Greenland Ice Core Data Show Abrupt Climate Change Happens in Few Years, Science, 321, 680-684, doi:10.1126/science.1157707, 2008.

Suwa, M., von Fischer, J. C., Bender, M. L., Landais, A., and Brook, E. J.: Chronology reconstruction for the disturbed bottom section of the GISP2 and the GRIP ice cores: Implications for Termination II in Greenland, J. Geophys. Res.-Atmos., 111, D02101, doi:10.1029/2005JD006032, 2006.

Svensson, A., Durand, G., Mathiesen, J., and Persson, A., and DahlJensen, D.: Texture of the Upper $1000 \mathrm{~m}$ in the GRIP and NorthGRIP Ice Cores, Supp. Issue Low Temperature, Science, 68, 107-113, 2009.

Svensson, A., Bigler, M., Kettner, E., Dahl-Jensen, D., Johnsen, S., Kipfstuhl, S., Nielsen, M., and Steffensen, J. P.: Annual layering in the NGRIP ice core during the Eemian, Clim. Past, 7, 14271437, doi:10.5194/cp-7-1427-2011, 2011.
Thorsteinsson, T., Kipfstuhl, J., and Miller, H.: Textures and fabrics in the GRIP ice core, J. Geophys. Res., 102, 26583-26600, 1997.

Thorsteinsson, T., Waddington, E. D., Taylor, K. C., Alley, R. B., and Blankenship, D. D.: Strain-rate enhancement at Dye 3, Greenland, J. Glaciol., 45, 338-345, 1999.

Wallbrecher, E.: Graphische, rechnerische und statistische, chap. Tektonische und gefügeanalytische Arbeitsweisen, p. 244, Verfahre, Enke, Stuttgart, 1986.

Wang, Y., Thorsteinsson, T., Kipfsuhl, J., Miller, H., Dahl-Jensen, D., and Shoji, H.: A vertical girdle fabric in the NGRIP deep ice core, North Greenland, Ann. Glaciol., 35, 515-520, 2002.

Wang, Y., Kipfstuhl, S., and Azuma, N.: Ice fabrics study in the upper $1500 \mathrm{~m}$ of the Dome C deep ice core, East Antarctica, Ann. Glaciol., 37, 97-104, 2003.

Wilson, C., Russell-Head, D., and Sim, H.: The application of an automated fabric analyzer system to the textural evolution of folded ice layers in shear zones, Ann. Glaciol., 37, 7-17, 2003. 